Eur. J. Clin. Chem. Clin. Biochem.

Vol. 32, 1994, pp. 429-434

(ㄷ) 1994 Walter de Gruyter \& Co.

Berlin · New York

\title{
The Detection, Quantification and Partial Characterisation of Cathepsin B-Like Activity in Human Pathological Synovial Fluids ${ }^{1}$
}

\author{
By J. M. Duffy, B. Walker, D. Guthrie, J. Grimshaw, G. McNally, J. T. Grimshaw, P. L. Spedding and \\ R. A. B. Mollan
}

The Body Fluids Research Team, The Queen's University of Belfast, Department of Orthopaedic Surgery, Musgrave Park Hospital, Belfast, Northern Ireland

(Received July 30, 1993/February 21, 1994)

Summary: In this study, the levels of the cysteine proteinase - cathepsin B were measured in diseased synovial fluids using a steady state fluorometric assay. Cathepsin B-like activity was shown to be present in all the samples analysed, with the rheumatoid arthritic synovial fluids possessing significantly higher concentrations (mean value ca. $416 \mathrm{mg} / \mathrm{l}$ ) than the osteoarthritic fluids (mean value ca. $142.4 \mathrm{mg} / \mathrm{l}$ ). In addition, upon treatment with pepsin, all of the rheumatoid arthritis samples were shown to possess additional cathepsin B-like activity, suggesting the presence of a reservoir of latent precursor molecules. By utilising a recently developed biotinylated affinity label for cathepsin B-like proteinases and sheep anti-(human cathepsin B) antibodies, used in combination with SDSPAGE and Western blotting, the rheumatoid arthritic synovial cathepsin B was shown to exist in two forms with apparent molecular masses of $M_{\mathrm{r}} 29000$ and 42000 . We propose that the former is a functionally active proteinase, whereas the latter is a pepsin activatable proform which, when cleaved by this aspartyl proteinase, is converted into a catalytically competent species of $M_{\mathrm{r}} 20000$.

\section{Introduction}

Arthritis encompasses almost 200 different illnesses, of which osteoarthritis and rheumatoid arthritis are the most widespread. With the limited availability of biochemical markers, early diagnosis is almost impossible and referral, to the clinic is usually the result of the patient experiencing pain, stiffness and loss of joint function. In a large majority of patients, the disease has progressed to such a degree, that the only remaining remedial action of total joint replacement. In the majority of the main classes of arthritic disease such as osteoartbritis and rheumatoid arthritis, there is massive degradation of the articular cartilage - the cushion in the synovial joint - causing the increase in pain and loss of joint function (1). Much attention has been di-

\footnotetext{
1) Funding Organisations

The Department of Education for Northern Ireland, Rathgael House, Balloo Road; Bangor, Co Down BT19 7PR
}

rected towards identifying those agents that are capable not only of bringing about such destruction of the articular surfaces, but also of the synovial fluid, the mechanical properties of which are also known to deteriorate with disease (1). One class of agents thought to be capable of such degradation are the proteinases and, in particular, much attention has focused on the possible involvement of the cysteine proteinases in arthritic disease (2).

It is known, for example, that cathepsin B is secreted from rheumatoid synoviocytes into the synovial fluid and thus may be involved in the in vivo degradation of connective tissue proteins (2). This thesis seems all the more reasonable in light of the in vitro studies demonstrating that cathepsin B can degrade various connective tissue constituents such as collagen and proteoglycans $(3-5)$. Under normal circumstances, any cathepsin B that is secreted/released into the synovial fluid is efficiently neutralised by proteinaceous inhibitors such as 
haptoglobulin and $\alpha_{2}$-macroglobulin (6), three $\alpha_{1}$ and $\alpha_{2}$ thiol protease inhibitors $(7-9)$ and the cystatins such as cystatin C (10). In contrast, in diseased conditions, an imbalance is thought to exist between proteinase and inhibitor - in favour of the former, and the proteinases are free to degrade the articular cartilage and other tissues in the joint (11). Other studies have demonstrated the possible therapeutic value of developing selective cathepsin B inhibitors based on the peptidyl fluoromethyl ketones $(12,13)$.

It is against this background that we have undertaken this present study on the detection, quantification and partial characterisation of cathepsin B-like proteinases in the synovial fluid of patients suffering from osteoarthritis and rheumatoid arthritis. This has been achieved by a combination of methods including steady-state fluorimetric assays and a recently developed Western blotting technique utilising a biotinylated affinity label for cathepsin B-like proteinases $(14,15)$.

\section{Materials and Methods}

\section{Sample collection}

In order to analyse the enzymatic properties of synovial fluid, samples were collected from patients, who were undergoing joint replacement surgery at Musgrave Park Hospital Belfast, and also from patients at the Rheumatology Outpatient Clinic, Belfast City Hospital, Belfast. Diagnosis was determined according to the criteria outlined by the American Rheumatism Association (16). All samples were obtained in undiluted form immediately prior to surgical procedures. In addition, the relevant medical information and history was obtained, by the surgeon, in an accompanying proforma with each sample. The proforma was designed not only to assist in the diagnosis but to provide the medical information to explain the results in terms of the pathogenesis of the joint disease.

\section{Synthesis of affinity labels}

The diazomethane affinity labels, $\mathrm{N}$-benzyloxycarbonyl-phenylalanyl-alanine-diazomethane (Cbz-Phe-Ala- $\left.\mathrm{CHN}_{2}\right)^{2}$ ) and N-benzyloxycarbonyl-phenylalanyl-tyrosine(OBut)-diazomethane (CbzPhe-Tyr-(OBut)- $\mathrm{CHN}_{2}$ ) were prepared by the general procedures $(17,18)$ and had melting points in close agreement with the literature values (19). The biotinylated affinity label $\mathrm{N}$-biotinyl-phenylalanyl-alanine-diazomethane (Bio-Phe-Ala- $\mathrm{CHN}_{2}$ ) was prepared by the cited procedure (14)

\section{Sample preparation}

Each of the samples was centrifuged at $5000 \mathrm{~g}$ for $30 \mathrm{~min}$ in order to remove any contaminants such as blood and debris associated with the surgical operation. The supernatant was then stored at $-15^{\circ} \mathrm{C}$ prior to utilisation in the enzymatic analysis.

\section{Steady state assay}

Samples of synovial fluid were assayed for cathepsin B-like activity as described by Barrett \& Kirschke (20). In essence, samples

\footnotetext{
2) Abbreviations used

Bio, biotinyl; Cbz, benzyloxycarbonyl; Mec, 4-methylcoumarin-7$\mathrm{yl}$; OBut, $t$-butyl ether.
}

$(50 \mu \mathrm{l})$ wcre added to a solution of $(1 \mathrm{ml}) \mathrm{N}$-benzyloxycarbonylarginyl-arginyl-4-methylcoumarin (Cbz-Arg-Arg-NH-Mec) (Bachem, Bubendorf, Switzerland) $(50 \mu \mathrm{mol} / \mathrm{l})$ in $100 \mathrm{mmol} / \mathrm{l}$ sodium phosphate buffer, $\mathrm{pH} 6.4$ containing $1 \mathrm{mmol} / \mathrm{l}$ ethylenediaminetetraacetic acid disodium salt, $10 \mathrm{~g} / \mathrm{l}$ Brij 35 and $2 \mathrm{mmol} / \mathrm{l}$ cysteine, maintained at $37^{\circ} \mathrm{C}$. The rate of hydrolysis was monitored continuously by measuring the rate of increase in fluorescence at $455 \mathrm{~nm}$ (excitation wavelength $383 \mathrm{~nm}$ ) in a Pérkin-Elmer MPF 44B spectrofluorimeter. This substrate is hydrolysed by cathepsin B but not cathepsins H or L (20). However, since kallikrein is known to degrade this substrate (21), control assays were carried out in the presence of the active-site-directed inhibitor Cbz-Phe-Ala-CHN which inactivates cysteine- but not serine proteinases (22).

\section{Pepsin activation}

As pepsin-activatable precursor forms of cathepsin B-like proteinases have been detected in such fluids as ascitic fluid from patients with ovarian cancer $(23,24)$ and in medium conditioned by tumour breast cancer cells in culture (15). The activation protocol described by these workers was applied to the synovial fluid samples in order to reveal any latent cathepsin B precursors that may have been present. Synovial fluid samples were treated with pepsin (Sigma, final concentration: $20 \mathrm{mg} / \mathrm{l}$ ), in $0.1 \mathrm{~mol} / 1$ glycine $/ \mathrm{HCl}$ buffer $\mathrm{pH} 3.0$, at $37^{\circ} \mathrm{C}$. The resulting activity was then determined by a steady state assay measuring the turnover of the fluorogenic substrate Cbz-Arg-Arg-NH-Mec. The hydrolysis of the substrate was blocked by Cbz-Phe-Ala-CHN 2 . Time course studies revealed that maximum cathepsin B-like activity was generated after $60 \mathrm{mi}-$ nute exposure to pepsin. In the absence of pepsin, no activation of latent enzyme was observed in any of the samples studied.

\section{Characterisation of labelled proteinases}

\section{Labelling of proteinases}

To $0.5 \mathrm{ml}$ of centrifuged synovial fluid was added $0.5 \mathrm{ml}$ of 100 $\mathrm{mmol} / \mathrm{l}$ phosphate buffer, $\mathrm{pH} 6.4$, containing $2 \mathrm{mmol} / \mathrm{l}$ cysteine, $1 \mathrm{mmol} / \mathrm{l}$ ethylenediaminetetraacetic acid disodium salt and $10 \mathrm{~g} / \mathrm{l}$ Brij 35. Ten $\mu$ l of Bio-Phe-Ala-CHN 2 (1 mmol/l in methanol) were added to this, and the solution was then incubated for two hours at room temperature. Following this, $0.5 \mathrm{ml}$ of $400 \mathrm{~g} / \mathrm{l}$ trichloroacetic acid was added to precipitate out the proteinaceous material, the mixture was then centrifuged for $15 \mathrm{~min}$ at $5000 \mathrm{~g}$ and the supernatant was discarded. The pellet was then dissolved in $0.5 \mathrm{ml}$ of Laemmli treated buffer and then boiled for 10 min thus terminating the reaction between the enżyme and inhibitor.

\section{Electrophoresis}

One dimensional SDS electrophoresis was performed (25) with $10 \%$ slab gels run at a constant current of $30 \mathrm{~mA}$ using the Mighty Small II Apparatus (Hoefer Scientific). Biotinylated molecular weight standards (Sigma Chemicals, Poole, Dorset, UK) were employed on each gel.

\section{Western blotting}

Transfer of protein from gel to nitrocellulose (pore size: $0.2 \mathrm{~mm}$; Schleicher und Schüll, Dassel, Germany) was carried out by the cited method (26). The protein transfer was. carried out in 25 $\mathrm{mmol} / \mathrm{l}$ glycine $/ 192 \mathrm{mmol} / \mathrm{l}$ Tris $/ 200 \mathrm{~g} / \mathrm{l}$ methanol using a TransBlot Cell (Bio-Rad). The running time was $18 \mathrm{~h}$ at $100 \mathrm{~mA}$, with a constant temperature of $4^{\circ} \mathrm{C}$.

\section{Detection of labelled proteins}

'The nitrocellulose blot was stained for biotinylated proteins by overlaying with streptavidin/alkaline phosphatase. The nitrocellulose paper was firstly blocked by incubation for $30 \mathrm{~min}$ with a 
$50 \mathrm{~g} / \mathrm{l}$ solution of bovine serum albumin (Sigma) containing $1 \mathrm{~g} / \mathrm{l}$ merthiolate and $1 \mathrm{~g} / 1$ anti-foam agent (Sigma). Streptavidin/alkaline phosphatase (Vector Laboratories), diluted $1: 1000$ in blocking solution, was incubated with the nitrocellulose blot at room temperature for $2-4 \mathrm{~h}$ with agitation. The blot was then washed at least six times with $0.1 \mathrm{~mol} / 1 \mathrm{Tris} / \mathrm{HCl}, \mathrm{pH} 9.5$, containing $0.1 \mathrm{~mol} / 1$ $\mathrm{NaCl}$ and $5 \mathrm{mmol} / 1 \mathrm{MgCl}_{2}$ before the alkaline phosphatase activity was detected by using Nitro Blue Tetrazolium $(66 \mathrm{ml}$ of a $75 \mathrm{~g} / 1$ solution in $700 \mathrm{~g} / \mathrm{l} \mathrm{N}, \mathrm{N}$-dimethyl formamide/ $\mathrm{H}_{2} \mathrm{O}$ ) and 5-bromo-4chloro-indol-3-yl phosphate $(33 \mathrm{ml}$ of a $50 \mathrm{~g} / \mathrm{l}$ solution in $\mathrm{N}, \mathrm{N}-$ dimethyl formamide) in $10 \mathrm{ml}$ of the same buffer.

\section{Immunoblotting}

The proteinaceous precipitate from samples of synovial fluid not exposed to the biotinylated probe were subjected to electrophoresis and Western blotting as described for the biotinylated proteins. Antibody probing of the Western blots was then carried out (27). Sheep anti-human cathepsin B IgG (Serotec; used at 1:200 dilution) and donkey anti-sheep IgG conjugated to alkaline phosphatase (Serotec; used at 1:1000 dilution), were used as first and second antibodies respectively. Alkaline phosphatase activity was detected using Nitro Blue Tetrazolium and 5-bromo-4-chloroindol3-yl phosphate.

\section{Results and Discussion}

Comparison of cathepsin B levels in rheumatoid- and osteoarthritic synovial fluids

By measuring the rate of hydrolysis of the fluorogenic substrate Cbz-Arg-Arg-NH-Mec, cathepsin B-like activity was quantified in the synovial fluid of patients with various arthropathies. This activity could be completely inhibited by the general cysteine protease inhibitor iodoacetamide and, additionally, the activity was also inhibited by the broad spectrum affinity label for cysteine proteinases Cbz-Phe-Ala-CHN ${ }_{2}$ (22), but not by the specific cathepsin $\mathrm{L}$ inhibitor $\mathrm{Cbz}-\mathrm{Phe}-\mathrm{Tyr}(\mathrm{OBut})-\mathrm{CHN}_{2}$ (19). The exhibited inhibitor susceptibility taken in consideration with the specificity of the substrate (Cbz-ArgArg-NH-Mec), suggests that the observed activity was indicative of a cathepsin B-like proteinase and excludes the possibility that a kallikrein-like enzyme is responsible for the observed substrate hydrolysis.

The levels of active cathepsin B (mg/l) were calculated for each sample assayed, by reference to a standard solution of human cathepsin B - titrated against E-64 (20), and were then categorised by disease group (see fig. 1). Cathepsin B activity was detected in all synovial fluid samples studied, regardless of the disease process. Statistical analysis of these results was carried out using a statistical analysis package, SPSS for Windows 6.0 (SPSS Inc., USA). Both rheumatoid arthritis and osteoarthritis subgroups exhibited normal Gaussian distributions with the mean concentrations of cathepsin B shown to be significantly higher in rheumatoid arthritic synovial fluids (mean value $416 \pm 226 \mathrm{mg} / \mathrm{l}$ ) than in osteoarthritic fluids (mean value $142 \pm 80 \mathrm{mg} / \mathrm{l}$ ), where

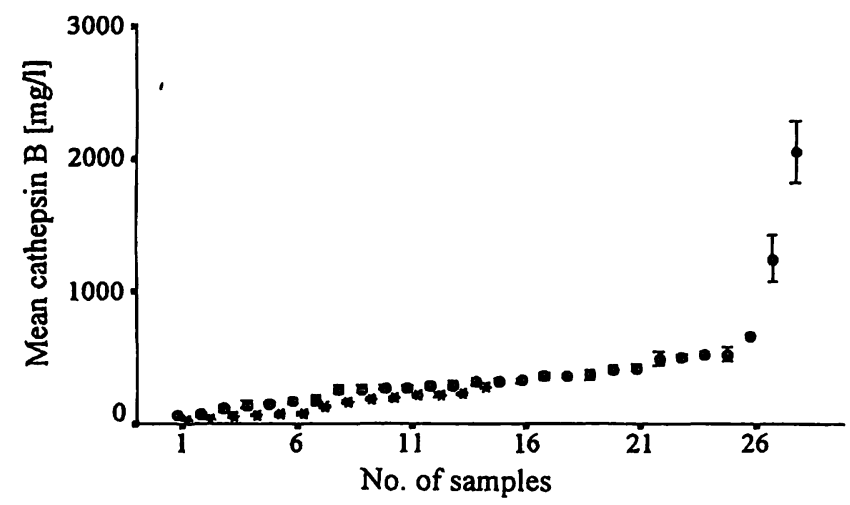

Fig. 1 Levels of cathepsin B-like activity in osteoarthritic (*) and rheumatoid arthritic (o) synovial fluids.

$p<0.001$ (28). Within the rheumatoid arthritis subgroup, the large associated standard deviation can largely be attributed to two statistical outlying samples, that contain enormously high amounts of the proteinase (1269 $\pm 29 \mathrm{mg} / \mathrm{l}, 2048 \pm 25 \mathrm{mg} / \mathrm{l})$, however, even with these out-lying values excluded, the mean value for the rheumatoid arthritic samples $(320 \mathrm{mg} / \mathrm{l})$ is still significantly greater than that of the osteoarthritic samples. Discriminant analysis of the cathepsin B levels revealed a $72 \%$ correct classification by disease subgroup highlighting the potential of this steady state assay as a diagnostic tool. Such results are in general agreement with other workers who, by using ELISA (11) and radioimmuno assay techniques (29), also found, on average, that cathepsin B levels were higher in rheumatoid arthriticwhen compared with osteoarthritic synovial fluids and sera.

A possible explanation for these findings can be found in the observation that Cathepsin B has been detected in the synovial membrane where it is thought to originate from synoviocytes $(30,31)$. The higher levels of cathep$\sin B$ in rheumatoid arthritic synovial fluid may therefore be attributed to the fact that the disease is, unlike osteoarthritis, inflammatory in nature and inflammation of the synovial membrane may cause an increase in the protease secretory output of the synoviocytes. Additionally, inflammation of the synovium may also cause an influx of such cells as macrophages which may also be responsible for the secretion of cathepsin $B$ and other proteases into the synovial fluid. It is known, for example, that collagenase levels are elevated in diseased, particular inflammatory, conditions again suggesting that proteolytic degradation may play an important role in arthritic disease (32). Cathepsin B has also been identified by other workers in rheumatoid synovial fluid (31) and also in synovial fluid with various forms of arthritis (33), using immunochemical methods. 
Western blot analysis of cathepsin B using Bio-Phe-Ala-CHN 2

To more fully characterise the activity present in the diseased synovial fluid, samples that had been incubated with the biotinylated affinity label Bio-Phe-Ala- $\mathrm{CHN}_{2}$ were subjected to SDS-PAGE on $10 \%$ slab gels, as detailed in the Materials and Methods section. This affinity label has been demonstrated to react covalently at the active-site of bovine and human cathepsin B, thus enabling their detection - following Western blotting, by utilising various streptavidin/enzyme labels $(14,15)$. Utilising this methodology, we were able to detect two major bands of apparent $M_{\mathrm{r}} 42000$ and 29000 (fig. 2, lane 3 ). The lower molecular weight form migrates with the same mobility as active lysosomal cathepsin B (20), and is in accordance with values reported by other workers, who have also identified a specific band of $M_{\mathrm{r}}$ 29000 in synovial fluid (11).

Since this biotinylated affinity label has been demonstrated to inactive both cathepsin B and L (34), it is necessary to carry out pre-incubation experiments with specific inactivators of cathepsin $\mathrm{L}$ that will block the incorporation of the biotinylated probe into this proteinase thus enabling one to unambiguously identify labelled bands as being cathepsin B-like. When samples of rheumatoid arthritic synovial fluid were pre-treated with Cbz-Phe-Tyr(OBut)-CHN 2 (0.1 mmol/l, for $30 \mathrm{~min}$ at $37^{\circ} \mathrm{C}$ ) which is just such an inactivator (19), no diminution in the incorporation of the biotinylated probe was observed (compare lane 5 - pre-treated sample with

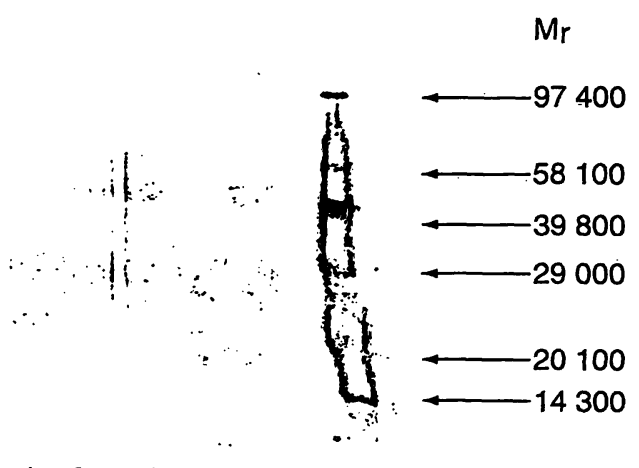

$\begin{array}{lllllll}1 & 2 & 3 & 4 & 5 & 6 & 7\end{array}$

Fig. 2 Western blot of synovial fluid samples utilising biotinylated affinity labels.

Lane 1 synovial fluid - pepsin activated, probed with anti-(cathepsin B) antibody

Lane 2 synovial fluid probed with anti-(cathepsin B) antibody

Lane 3 synovial fluid pretreated with Biotin-Phe-Ala-CHN

Lane 4 synovial fluid - pepsin activated, pretreated with BiotinPhe-Ala-CHN,

Lane 5 synovial fluid pretreated with Cbz-Phe-Tyr(OBut)-CHN and Biotin-Phe-Ala-CHN 2

Lane 6 synovial fluid pretreated with Cbz-Phe-Ala-CHN $\mathrm{CH}_{2}$ and Biotin-Phe-Ala-CHN 2

Lane 7 biotinylated molecular weight markers lane 3 - no pre-treatment). This further strengthens our case that the species of $M_{\mathrm{r}} 42000$ and 29000 are cathepsin B-like. In addition earlier studies have shown that human cathepsin B- $\alpha_{2}$-macroglobulin complexes were not detectable with this biotinylated probe (unpublished results) therefore it is unlikely' that the steady state assay was detecting such complexes. Moreover, we consider it likely that the species of $M_{\mathrm{r}} 29000$ is the active proteinase which is detected in the steady state assay and the $M_{\mathrm{r}} 42000$ form is possibly a pro-form of this proteinase.

We have previously observed a similar banding pattern for a cathepsin B-like species produced by human breast cancer cells in culture (15) and in this particular instance the high molecular weight species could be converted, via activation with pepsin, into a $M_{\mathrm{r}} 29000$ form capable of cleaving the fluorogenic substrate (Cbz-Arg=ArgNH-Mec.

In order to test whether the $M_{\mathrm{r}} 42000$ species did actually constitute a latent - but activatable reservoir of proteolytically active cathepsin $\mathrm{B}$, we treated a series of synovial fluid samples with pepsin, essentially according to the protocols described in previous work $(23,24)$. Figure 3 records the levels of these latent activities. From this figure it can be appreciated that all of the rheumatoid arthritis-synovial samples possess latent cathepsin B-like activity. When this activation step was carried out in the absence of pepsin, but using the same buffer system $(0.1 \mathrm{~mol} / 1$ glycine $/ \mathrm{HCl}, \mathrm{pH} 3.0)$, no additional activity was generated. This would tend to exclude the possibility that the $M_{\mathrm{r}} 42000$ band is a cathep= sin L precursor, since these species are known to be efficiently activated by mild acid treatment alone (35, $36,37)$. Additionally, the fact that this pepsin-generated activity could cleave $\mathrm{Cbz}-\mathrm{Arg}=\mathrm{Arg}-\mathrm{NH}-\mathrm{Mec}$, also strengthens our assertion that the $M_{\mathrm{r}} 42000$ protein is a precursor of cathepsin $B$ and not of cathepsin $L$, since the latter is incapable of cleaving this fluorogenic substrate (20).

The inability of the $M_{\mathrm{r}} 42000$ species to hydrolyse the fluorogenic substrate $\mathrm{Cbz} \div \mathrm{Arg}=\mathrm{Arg}-\mathrm{NH}-\mathrm{Mec}$, but yet in-

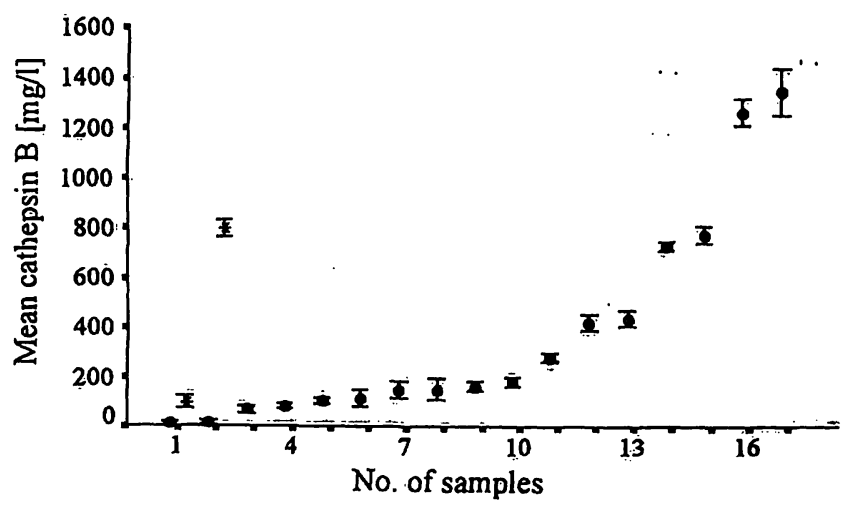

Fig. 3 Levels of latent cathepsin:B-like activity in osteoarthritic $(*)$ and rheumatoid arthritic (•) synovial fluids. 
corporate the biotinylated affinity label, appeared, at first sight, to represent something of a dichotomy. However, we also have observed just such behaviour with the pepsin activatable, latent cathepsin B-like species produced by human breast cancer cells in culture (15), and a recent report on the incorporation of an ${ }^{125}$ I-radiolabelled epoxide derivative $\mathrm{N}$-(2S,3S)-3-trans-ethoxycarbonyloxirane-2-carbonyl- $L$-tyrosine benzyl ester into the catalytically inactive prepro form of papain (38), corroborates our observations and would suggest that the proforms of the papain superfamily of cysteine proteinases do possess some inherent chemical reactivity towards certain active-site-directed affinity labels.

Therefore, we would offer the suggestion that rheumatoid arthritic synovial fluids not only contain active cathepsin B, but also a reservoir of a latent and activatable proform.

The molecular aspects of the pepsin-activation step were then analysed using the Western blotting protocols described above; figure 2 records the results of some of these studies. From this figure it can be seen that the higher molecular mass band $\left(M_{\mathrm{r}} 42000\right)$ disappears when the sample is treated with pepsin and then labelled with the biotinylated inhibitor (fig. 2, lane 4). In light of our studies carried out on the human breast cancer cellassociated cathepsin B mentioned above (15), we had expected to find that this decrease in the $M_{\mathrm{r}} 42000$ form would be accompanied by a corresponding increase in the $M_{\mathrm{r}} 29000$ species; but this was not the case. Rather, it wàs noted that a new species was generated of $M_{\mathrm{r}}$ 20000 . We presume that this is the species that is responsible for the 'additional' turnover of Cbz-Arg-Arg$\mathrm{NH}-\mathrm{Mec}$ that is observed upon pepsin treatment of the samples.

\section{Immunological characterisation of cathepsin B-like species}

In order to further the case for the presence of a cathepsin B-like species in synovial fluid, immunological analysis of samples not exposed to the biotinylated probe was carried out. Probing of such samples with anti-(cathepsin B) antibodies gave results exactly comparable to those with the biotinylated probe, thus we were again able to detect the two major bands of apparent $M_{\mathrm{r}} 42000$ and 29000 (fig. 2, lane 2). Immunoblotting of pepsin-activated synovial fluid samples also yielded completely symmetrical results when compared to the biotinylated probe (fig. 2, lane 1) complete with the generation of the new species $M_{\mathrm{r}} 20000$. The detection and characterisation, using antibodies raised against active human cathepsin $B$, of latent forms of the proteinase has been previously reported, malignant ascites cells in culture are known to produce a $M_{\mathrm{r}} 40000$ proform of the enzyme which can be converted into a $M_{\mathrm{r}} 33000$ species by pepsin activation (24).

The absolute symmetry between the results of the labelling with the biotinylated probe and the anti-(cathepsin B) antibodies, in combination with the lack of autocatalysis of the latent form in acidic medium alone, lends further support to our thesis that we are detecting a latent pepsin-activatable and an active form of cathepsin $B$.

\section{Conclusions}

1. By inference to substrate specificity, inhibitor susceptibility and molecular weight $\left(M_{\mathrm{r}} 29000\right)$ - a cathepsin B-like species was shown to be present in the synovial fluid of patients suffering from osteoarthritis and rheumatoid arthritis.

2. By steady state analysis significantly elevated levels of cathepsin B-like activity were found in rheumatoid arthritic synovial fluid when compared to osteoarthritic fluid - thus suggesting a possible role for this proteinase in arthritic disease coupled with possible diagnostic potential.

3. The action of pepsin revealed the presence of additional cathepsin B-like activity in both osteoarthritic and rheumatoid arthritic synovial fluid by steady state analysis.

4. Western blot analysis of synovial fluid revealed the presence of a higher molecular weight band $\left(M_{\mathrm{r}} 42000\right)$ - thought to be a pepsin-activatable form of cathepsin $B$ and possibly responsible for the additional activity observed in the pepsin steady state assay.

5. Immunoblotting of fluid samples not treated with the biotinylated probe, using anti-(cathepsin B) antibodies, yielded completely symmetrical results when compared to the Western blots using the probe, both before and after pepsin treatment. Thus lending further support to the thesis that we have detected a latent but pepsin-activatable and an active form of cathepsin B in synovial fluid.

6. In this work we have demonstrated the utilisation of the recently developed biotinylated affinity label Biotinyl-Phe-Ala-Diazomethane (Bio-Phe-Ala- $\mathrm{CHN}_{2}$ ) for the detection of an active and a pepsin-activatable form of a cathepsin B-like enzyme in diseased synovial fluid.

\section{Acknowledgement}

This work was made possible by funding by the Department of Education for Northern Ireland.

The samples of synovial fluid were obtained from the Orthopaedic Theatres at Musgrave Park Hospital and from the Outpatient Clinic at the Belfast City Hospital organised by Dr. A. Taggart, Dept Rheumatic Diseases, Musgrave Park Hospital, Belfast. 


\section{References}

1. Schur, J. \& Ribitsch, H. (1987) Rheology of synovial fluid. Biorheology 24, 385-399.

2. Woessner, J. F. \& Howell, D. S. (1983) Studies in Joint Disease, Vol. 2 (Maroudas, A. \& Holborow, E. J., eds) Pitman, London, UK.

3. Morrison, R. I. G., Barrett, A. J., Dingle, J. T. \& Prior, D. (1973) Cathepsins B1 and D - Action on human Cartilage proteoglycans. Biochim. Biophys. Acta 302, 411-419.

4. Etherington, D. J. (1974) The purification of bovine cathepsin $\mathrm{B} 1$ and its mode of action on bovine collagens. Biochem. J. 137, 387-398.

5. Roughley, P. J. \& Barrett, A. J. (1977) The degradation of cartilage proteoglycans by tissue proteinases. Proteoglycan heterogeneity and the pathway of proteolytic degradation. Biochem. J. 167, 629-637.

6. Starkey, P. M. (1973) Binding and inhibition of cathepsin B1 by $\alpha_{2}$-macroglobulin. Biochem. Soc. Trans. 1,380 .

7. Sasaki, M., Taniguchi, K. \& Minakata, K. (1981) Multimolecular forms of thiol proteinase inhibitors in human plasma. J. Biochem. 89, 169-177.

8. Ghosh, P., Andrews, J. L., Osborne, R. A. \& Lesjak, M. S. (1986) Variation with ageing and degeneration of the serine and cysteine protease inhibitors of human articular cartilage. Agents Action 18, 69-81.

9. Lenney, J. F., Liao, J. R., Sugg, S. L., Goplakrishman, V., Wong, H. C. H., Ouye, K. H. \& Chan, P. W. (1982) Low molecular weight inhibitors of cathepsin $B, H$, and $T$ in human serum, synovial fluid and CSF. Biochem. Biophys. Res. Comm. 108, 1581-1587.

10. Turk, V. \& Bode, W. (1991) The cystatins: Protein inhibitors of cysteine proteinases. FEBS Lett. 285, 213-219.

11. Gabrijelcic, D., Annan-Rah, A., Rodic, B., Rozman, B., Cotic, V. \& Turk, V. (1990) Determination of cathepsin B and H in sera and synovial fluids of patients with different joint diseases. J. Clin. Chem. Clin. Biochem. 28, 149-153.

12. Ahmed, N. K., Martin, L. A., Watts, L. M., Palmer, J., Thornburg, L., Prior, J. \& Esser, R. E. (1992) Peptidyl fluoromethyl ketones as inhibitors of cathepsin B; Implication for treatment of rheumatoid arthritis. Biochem. Pharmacol. 44, 1201-1207.

13. Van Noorden, C. J. F., Smith, R. E. \& Rasnick, D. (1988) Cysteine proteinase activity in arthritic rat knee joints and the effects of a selective systemic inhibitor, Z-Phe- $\mathrm{AlaCH}_{2} \mathrm{~F}$. J. Rheumatol. 15, 1525-1535.

14. Walker, B., Cullen, B. M., Kay, G., Halliday, I. M., McGinty, A. \& Nelson, J. (1992) The synthesis, kinetic characterisation and application of a novel biotinylated affinity label for cathepsin B. Biochem. J. 283, 449-453.

15. Cullen, B. M., Halliday, I. M., Kay, G., Nelson, J. \& Walker, B. (1992) The application of a novel biotinylated affinity label for the detection of a cathepsin B-like precursor produced by breast tumour cells in culture. Biochem. J. 283, 461-465.

16. Ropes, M. V., Bennett, G. A., Cobb, S., Jacox, R. \& Jessar, R. A. (1958) Revision of the diagnostic criteria for rheumatoid arthritis. Bull. Rheum. Dis. 9, 175-176.

17. Shaw, E., Wikstrom, P. \& Euscia, J. (1983) An exploration of the primary specificity site of cathepsin B. Arch. Biochem. Biophys. 222, 248-265.

18. Shaw, E. \& Green, G. D. (1981) Inactivation of thiol proteases with peptidyl diazomethyl ketones. Methods Enzymol. 80, 820-826.

19. Kirschke, H., Wikstrom, P. \& Shaw, E. (1988) Active centre differences between cathepsin $L$ and cathepsin B - The S1 binding region. FEBS Lett. 228, 128-130.

20. Barrett, A. J. \& Kirschke, H. (1981) Cathepsin B, cathepsin H and cathepsin L. Methods Enzymol. 80, 535-550.
21. Mort, J. S. \& Leduc, M. C. (1984) The combined action of 2 enzymes in human serum can mimic the activity of cathepsin B. Clin. Chim. Acta 140, 173-182.

22. Green, G. D. \& Shaw, E. (1981) Peptidyl diazomethyl ketones are specific inactivators of thiol proteinases. J. Biol. Chem. 256, $1923-1928$.

23. Mort, J. S., Leduc, M. \& Recklies, A. D. (1981) A latent thiol protease from ascitic fluid of patients with neoplasia. Biochim. Biophys. Acta $662,173-180$.

24. Mort, J. S., Leduc, M. \& Recklies, A. D. (1983) Characterisation of a latent cysteine proteinase from ascitic fluid as a high molecular weight form of cathepsin B. Biochim. Biophys. Acta $775,369-375$.

25. Laemmli, U. K. (1970) Cleavage of structural proteins during the assembly of the head of bacteriophage T4. Nature 227, $680 \div 685$.

26. Towbin, H., Staehelin, T. \& Gordon, J. (1979) Electrophoretic transfer of proteins from polyacrylamide gels to nitrocellulose sheets: Procedure and some applications. Proc. Natl. Acad. Sci. USA $76,4350-4354$.

27. Maciewicz, R. A. \& Knight, P. J. (1988) Transmission densitometry of stained nitrocellulose paper. Anal. Biochem. 175, $85-90$.

28. Wonnacott, T. H. \& Wonnacott, R. J. (1977) Introductory Statistics, 3rd Edition (Bradley, R. A., Hunter, J. S., Kendall, D. G. \& Watson, G., eds.) Wiley, S. J. and Sons Inc., New York, USA.

29. Recklies, A. D. \& Mort, J. S. (1982) A radioimmunoassay for total human cathepsin B. Clin. Chim. Acta 123, 127-138.

30. Codorean, E., Buzila, L. \& Gabrielescu, E. (1981) Immunocytochemical investigation of cathepsin $B$ in the rheumatoid synovial membrane and fluid. Rev. Roum. Biochim. 18, 241-247.

31. Codorean, E. \& Gabrielescu, E. (1985) Cytochemical investigation of cathepsin $B$ in rheumatoid synovial membrane and fluid. Morphol. Embryol. 31, 269-274.

32. Gysen, P., Malaise, M., Gaspar, S. \& Franchimount, P. (1985) Measurement of proteoglycans, elastase, collagenase and protein in synovial fluid in inflammatory and degenerative arthropathies. Clin. Rheumatol. 4, 39-50.

33. Maciewicz, R. A. \& Etherington, D. J. (1988) Enzyme immunoassay for cathepsin $B$ and $L$ in synovial fluids from patients with arthritis. Biochem. Soc. Trans. 16, 812-813.

34. McGinty, A. (1991) Ph. D. Thesis: The Design, Synthesis and Application of Novel Inhibitors of Cysteine Proteinases. The Queen's University of Belfast.

35. Gal, S. \& Gottesman, M. M. (1986) The major excreted protein of transformed fibroblasts is an activatable acid proteinase. J. Biol. Chem. 261, 1760-1765.

36. Gal, S. \& Gottesman, M. M. (1986) The major excreted protein (MEP) of transformed mouse cells and cathepsin $L$ have similar protease specificity. Biochem. Biophys. Res. Commun. $139,156-162$.

37. Troen, B. R., Gal, S. \& Gottesman, M. M. (1987) Sequence and expression of the cDNA for MEP (major excreted protein) a transformation regulated secreted cathepsin. Biochem. J. $246,731-735$.

38. Vernett, T., Khouri, H. E., Tesier, D. C., Laflamme, P., Storer, A. C. \& Thomas, D. Y. (1991) Processing of the papain precursor - Purification of the zymogen and characterisation of its mechanism of processing. J. Cell. Biochem. Suppl. 15G, $\mathrm{CH}$ 319.

Dr J. M. Duffy

The Queen's University of Belfast

Department of Orthopaedicisurgery

Musgrave Park Hospital

Belfast BT9 $7 \mathrm{JB}$

Northern Ireland 